\title{
Correction to "Quantitative Contribution of Six Major Transporters to the Hepatic Uptake of Drugs: SLC-Phenotyping Using Primary Human Hepatocytes"
}

In the above article [Bi Y-A, Costales C, Mathialagan S, West M, Eatemadpour S, Lazzaro S, Tylaska L, Scialis R, Zhang H, Umland J, Kimoto E, Tess DA, Feng B, Tremaine LM, Varma MVS, and Rodriques AD (2019) J Pharmacol Exp Ther 370(2): 72-83; DOI: https://doi.org/ 10.1124/jpet.119.257600], Renato Scialis's middle initial was omitted from the byline. He should be listed as Renato J. Scialis.

Additionally, the current affiliations of four of the authors at the time of publication were not noted. Footnotes should have indicated that: Laurie Tylaska's current affiliation is Cybrexa Therapeutics, New Haven, CT. Renato J. Scialis's current affiliation is Metabolism and Pharmacokinetics, Preclinical Candidate Organization, Bristol-Myers Squibb, Princeton, NJ. Bo Feng's current affiliation is Drug Metabolism and Pharmacokinetics Group, Vertext Pharmaceutics, Boston, MA. Larry M. Tremaine's current affiliation is Tremaine DMPK Consulting, LLC, Merritt Island, FL.

The PDF and HTML versions of the article have been corrected.

The authors apologize for any inconvenience caused by these errors. 